ISSN 1981-416X

Licenciado sob uma Licença Creative Commons

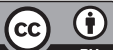

\title{
Autonomia e autoridade científicas na educação: um campo dialógico e compreensivo
}

\author{
Scientifics authority and autonomy in education: \\ a dialogic and comprehensive field
}

Autonomía y autoridad científicas en la educación: un campo dialógico y comprensivo

\section{Rodrigo Avila Colla*}

Pontifícia Universidade Católica do Rio Grande do Sul (PUCRS), Porto Alegre, RS, Brasil

\section{Resumo}

O presente artigo propõe uma atualização da teoria dos campos de Pierre Bourdieu para repensar os parâmetros usados para aferir o grau de autonomia e autoridade científicas da Educação. Utiliza-se de revisão teórica de autores Bourdieu (1983; 2003; 2004), Bernard Lahire (2002), Bernard Charlot (2006), Boaventura de Sousa Santos (2004; 2008), Hans-Georg Gadamer (1999), José Carlos Libâneo (2005) e Émile Durkheim (2007; 2011). Parte-se do pressuposto de que no contexto contemporâneo, onde a heterogeneidade de demandas se intensifica, e num campo com suas especificidades, neste caso a Educação, é preciso pensar na autonomização e na busca por autoridade científica em outros termos. Sugere-se o diálogo compreensivo interdisciplinar e entre agentes internos e externos do

*RAC: Doutor em Educação, e-mail: rodrigo.a.colla@gmail.com 
campo como alternativa para obtenção de reconhecimento (autoridade científica) e autonomia, levando em conta as particularidades do campo da Educação.

Palavras-chave: Autonomia e Autoridade Científicas. Ciências da Educação. Pierre Bourdieu. Sociologia da Educação. Teoria dos Campos.

\begin{abstract}
This article proposes an update of the Pierre Bourdieu's fields theory to rethink the parameters used to assess the degree of scientific autonomy and authority in the education field. It uses theoretical review of authors as Bourdieu himself (1983, 2003, 2004), Bernard Lahire (2002), Bernard Charlot (2006), Boaventura de Sousa Santos (2004, 2008), Hans-Georg Gadamer (1999), José Carlos Libâneo (2005) and Émile Durkheim (2007; 2011). This is on the assumption that in the contemporary context, where the heterogeneity of demands intensifies, and a field with its specificities, in this case the Education, it is necessary to think about empowerment and the pursuit of scientific authority in other terms. It is suggested interdisciplinary dialogue and understanding among internal and external actors of the field as an alternative to obtaining recognition (scientific authority) and autonomy considering the particularities of the field of Education.
\end{abstract}

Keywords: Scientific Autonomy and Authority. Science of Education. Pierre Bourdieu. Sociology of Education. Fields Theory.

\title{
Resumen
}

El presente artículo propone una actualización de la teoría de los campos de Pierre Bourdieu para repensar los parámetros usados para medir el grado de autonomía y autoridad cientifica de la Educación. Utilizase de revisión teórica de autores como el propio Bourdieu (1983; 2003; 2004), Bernard Lahire (2002), Bernard Charlot (2006), Boaventura de Sousa Santos (2004; 2008), Hans-Georg Gadamer (1999), José Carlos Libâneo (2005) y Émile Durkheim (2007; 2011). Se parte del supuesto de que en el contexto contemporáneo, donde la heterogeneidad de demandas se intensifica, y en un campo con sus especificidades, en este caso la 
Educación, es preciso pensar en la autonomización y en la búsqueda por autoridad científica en otros términos. Se sugiere el diálogo comprensivo interdisciplinario y entre agentes internos y externos del campo como alternativa para la obtención de reconocimiento (autoridad científica) y autonomía teniendo en cuenta las particularidades del campo de la Educación.

Palabras clave: Autonomía y Autoridad Científica. Ciencias de la Educación. Pierre Bourdieu. Sociología de la Educación. Teoría de los Campos.

\section{Apresentação}

Neste ensaio se pretende refletir acerca de alguns aspectos inerentes à pesquisa em Educação que, com frequência, obstaculizam a absorção de resultados de estudos, tanto pelos profissionais da área, de modo independente, os considerando em suas práticas, como pelas políticas educacionais. De modo semelhante, não raro, as pesquisas em educação são vistas com menos credibilidade em virtude da sua natureza e da posição que, consequentemente, a Educação (ou as Ciências da Educação), enquanto disciplina, ocupa no campo científico. Trata-se de um campo heterogêneo, com uma miríade de interpenetrações de outras áreas do conhecimento, cujas demandas são forjadas em grande medida no âmbito social. Porém, se a Educação é constituída por diversas disciplinas, o mesmo não se pode dizer da Pedagogia. Esta é uma das ciências a serviço da educação.

Este texto se propõe discutir a Educação como campo e, para tanto, a Pedagogia também é tematizada como uma ciência. Desde já é importante salientar que, por se tratar de uma ciência que pensa quase que exclusivamente a educação, a pedagogia apresenta os mesmos sintomas de falta de autonomia e autoridade científicas.

Para levar essa discussão à tona, serão de extrema contribuição, sobretudo, os trabalhos de Pierre Bourdieu (1983; 2003; 2004) e Bernard Charlot (2006). Ademais, com o intuito de sugerir uma dinâmica que permita repensar os parâmetros de busca da autonomia no campo educativo, 
se buscará respaldo principalmente nas obras de Hans-Georg Gadamer (1999) e Boaventura de Sousa Santos (2004; 2008).

Num primeiro momento será esclarecida brevemente a teoria dos campos de Bourdieu. Após, serão discutidas características do campo da educação que o constituem como campo com baixo grau de autonomia e apresentadas algumas regularidades que podem lhe servir como fatores autonomizante, por assim dizer. Por fim, se reflete sobre estratégias específicas de discussão coletiva para promover a autonomização da Educação enquanto campo e outorgarlegitimação à autoridade científica dos pesquisadores que se dedicam a estudos educacionais.

\section{Campos de Embates: ciências em disputa}

A articulação da ciência com a política é um tema extremamente relevante que, por certo, mereceria mais atenção por parte de estudiosos da ciência, principalmente sociólogos e filósofos, buscando com isso impulsionar a criticidade dos cientistas no que diz respeito a esse assunto. A autoanálise de suas práticas sob os prismas sociológico e filosófico teria muito a contribuir na reflexão sobre o papel social da ciência. Com isso, quiçá fosse possível repensar a postura do intelectual e encetar a forja de um habitus científico mais engajado politicamente e mais consciente de sua responsabilidade para com a sociedade.

Bernard Lahire (2002), notável discípulo de Pierre Bourdieu, esclarece que a teoria dos campos dá continuidade à tradição sociológica que dá especial atenção a diferenciação histórica das atividades humanas e seu funcionamento calcadas numa perspectiva de divisão social do trabalho. A ciência não escapa ao forte teor diferencial da sociedade. Lahire (2002), entretanto, critica a teoria pelo fato de promover uma dupla exclusão: dos agentes que estão fora do campo e das atividades realizadas pelos agentes do campo fora dele. Ou seja, segundo este autor, trata-se de uma teoria empenhada em desvelar relações de poder inerentes a contextos específicos. Com isso, serve, por exemplo, para analisar atividades profissionais, mas 
não integra em sua análise os desempregados e nem as atividades realizadas pelos empregados em outros quadros sociais. Nesse viés,

[...] a teoria dos campos constitui uma maneira de responder a uma série de problemas científicos mas, por sua vez, pode constituir um obstáculo ao conhecimento do mundo social (sobretudo quando o campo se torna o alfa e o ômega de toda contextualização das práticas) [...] (LAHIRE, 2002, p. 51).

Por isso, para Lahire (2002), a teoria dos campos não pode ser universalizável nem respaldar argumentos com fins generalizadores, mas pode, porém, contribuir nas análises "regionais". Essa problemática levantada por Lahire será interessante retomar logo adiante quando nos ativermos ao campo específico da Educação. Por ora, cabe nos aprofundarmos um pouco mais em certos aspectos da teoria de Bourdieu.

Bourdieu (1983) explicita seu conceito de campo científico chamando atenção para o fato de seu funcionamento não ser isento de interesses específicos: trata-se de um jogo concorrencial, um espaço de disputas. Não é à toa, assim, que certos pesquisadores construam suas trajetórias voltando-se mais para cargos políticos e burocráticos no campo das instituições de pesquisa, enquanto que outros optam por se ocupar quase estritamente de suas pesquisas e da produção científica. São posicionamentos que definirão o grau e o tipo específico de reconhecimento que o cientista auferirá e influenciarão o grau em que obterão capital científico.

Bourdieu (2004) esclarece que o capital científico é uma espécie particular de capital simbólico que se funda em atos de conhecimento e reconhecimento. Ou seja, é o reconhecimento de determinada competência do cientista pelos membros do campo que lhe atribuirá autoridade científica, seja ela para a gestão política, seja para a pesquisa. Há, assim, dois tipos de capital científico: o puro, aquele obtido por meio de pesquisas com descobertas e contribuições científicas; e o institucionalizado, que é auferido por presença política em cargos diretivos, em bancas examinadoras, em comissões, etc.

No centro da discussão acerca do campo científico estão também as questões dos graus de autonomia do pesquisador e do campo disciplinar em que está inserido. Nas palavras de Bourdieu (2004, p. 74), “[...] quanto 
mais se é autônomo, mais se tem chance de dispor da autoridade específica, isto é, científica ou literária, que autoriza a falar fora do campo com uma certa eficácia simbólica". A autonomia do pesquisador está intrinsecamente ligada ao capital científico por ele obtido. A autonomia de um campo, por sua vez, dependerá do grau de influência que sofre de outros campos.

Cabe deter-se um pouco mais neste ponto e refletir sobre a autonomia no campo da Educação.

\section{A Natureza do Campo Educativo}

Bernard Charlot (2006, p. 8) admite que "não existe pesquisa educacional, e sim uma pesquisa sociológica, psicológica, didática etc. sobre temas ligados à educação". Apesar de essa afirmação ser passível de crítica, uma vez que Charlot não faz referência à Pedagogia —embora a didática possa ser considerada uma disciplina pedagógica, o autor não faz uma referência explícita à Pedagogia —, ela já explicaria, em grande medida, o fato da Educação sofrer com a falta de estatuto disciplinar e, consequentemente, com a falta de autonomia científica. Libâneo (2005) esclarece a distinção entre Educação e Pedagogia e considera a Pedagogia como uma das ciências da educação. Durkheim (2011) já havia se dedicado a esse tema em Educação e Sociologia, mas Libâneo (2005) demonstra preocupação em demarcar o estatuto disciplinar da Pedagogia e justificar a sua importância. O esforço de Libâneo (2005) nesse sentido não deixa de ser um indicativo de que, detentora de pouca autonomia e autoridade científicas, a Pedagogia, diferente de outras disciplinas, precisa dessa defesa.

O campo da Educação não somente se constitui com intervenções de pesquisadores dessas áreas citadas por Charlot (2006) como também sofre mais fortemente que outras disciplinas a influência das políticas de Estado e das demandas que se forjam no ideário da sociedade (os modismos, as tendências, os câmbios na cultura dominante, os embates da diversidade cultural, de gênero, de etnia, religiosa, enfim, os fluxos sociais de modo geral). Maria Cecília de Souza Minayo (2010) explica que, 
pelo menos nas ciências humanas e sociais, para que se formule um problema de pesquisa, este há de ter sido antes um problema na vida prática. Nota-se com isso que, em pesquisas em educação, na maioria dos casos não há como fugir da influência externa na formulação de demandas.

Incapaz de ter um elevado grau de autonomia nesse aspecto, segundo Charlot (2006), a regularidade constituinte da Educação enquanto disciplina, será justamente a presença das interpenetrações disciplinares referidas anteriormente bem como o fato de ser, em última instância, e em qualquer caso, um triplo processo no duplo sentido do termo, isto é, ao mesmo tempo de humanização, de socialização e de singularização, e articulado por uma tríade: agentes discentes, docentes e políticas institucionais e de gestão.

A dificuldade de estabelecer essa complexa imbricação no âmbito da pesquisa às vezes parece escamotear a possibilidade de a Educação arvorar para si o estatuto disciplinar e dos seus cientistas auferirem autonomia científica. Para tanto, conviria que a contemplação desse duplo tripé estivesse no seio das pesquisas em educação e houvesse esforço no sentido de se constituir uma "memória educativa", uma espécie de inventário das pesquisas feitas no campo, com a finalidade de, se calcando na historicidade dos estudos em educação, fornecer respaldo para que as próximas investigações pudessem ganhar em substancialidade (CHARLOT, 2006). Por outro lado, é patente a dificuldade de contemplar essas duas tríades em todos os casos. É nesse sentido que Charlot (2006, p. 17) se pergunta sobre como seria possível "construir uma disciplina organizada, passível de ser identificada”, e relata sua crença de que, subjacente à necessidade de salvaguardar a memória das pesquisas educacionais, está o problema dos pontos de partida dos estudos em educação. Para ele, as ciências ditas duras (as naturais) avançam a partir dos seus pontos de chegada, enquanto que as humanas desde seus pontos de partida. $\mathrm{Na}$ óptica do autor, esse caminho inverso dificulta a acumulação do conhecimento em ciências humanas e sociais, ou seja, em vez de desmembrar um objeto e catalogar e classificar suas especificidades, elas trabalham com a crescente complexificação dos seus agentes. Porém, se não há acumulação, frisa Charlot (2006), há de se estar atento à questão da memória cuja 
existência é inegável. Bourdieu parece reconhecer a dupla historicidade do ato científico como um dos fatores de coesão do campo:

Cada ato científico é, igual a qualquer outra prática, o produto do encontro entre duas histórias, uma história incorporada em forma de disposições e uma história objetivada na própria estrutura do campo nos objetos técnicos (os instrumentos), os textos, etc. (BOURDIEU, 2003, p. 67, tradução nossa).

Ou seja, há uma historicidade inerente ao modo de fazer ciência dos sujeitos da ciência, ao habitus científico dos pesquisadores, e outra que está interiorizada no próprio campo e se reflete em suas técnicas. Assim, há fatores forjados historicamente que permeiam a formulação e a formação - e porque não dizer também a formalização - das problemáticas e demandas, bem como há a evolução e desenvolvimento das técnicas que, por sua vez, também extrapolam a instância puramente pragmática e contaminam o modo de ser do cientista. Nas palavras de Bourdieu (2003, p. 68, tradução nossa), é possível identificar a interdependência dessas duas histórias: "as infinitas facetas de um tesouro, lentamente acumulado, de gestos calibrados e de atitudes convertidas em hábitos”.

Charlot (2006) chama atenção para um terceiro fator histórico: a memória de pesquisa (que, é claro, não deixa de sofrer influência das duas esferas de historicidade apontadas por Bourdieu). A questão da memória é muito bem exemplificada por Charlot (2006) deixando patente a necessidade de haver um inventário da historicidade do campo, uma vez que se trata de uma ciência que centra seus esforços investigativos desde os pontos de partida. Nesse sentido, ter um mapeamento histórico que permita estabelecer marcos iniciais e trajetórias de pesquisa possíveis é imprescindível. De qualquer maneira, parece haver no texto de Charlot (2006) certa carência de analogias mais precisas com a área da Educação, no que diz respeito à relação entre os seus objetos de pesquisa e o problema dos seus pontos de partida. Tentemos aclarar: os objetos de pesquisa educacionais geralmente envolvem sujeitos ou estes constituem o corpus da pesquisa. A investigação do pesquisador geralmente é prospectiva, ou seja, parte de uma situação-problema e analisa seus desdobramentos a partir da aplicação de algum instrumento, método ou 
proposta pedagógica ao longo de determinado tempo. Raras vezes é possível se lançar um olhar retrospectivo que, a partir do ponto de chegada, identifica e mensura variáveis que exerceram influência no curso dos acontecimentos. Isso porque não há controle sobre os objetos educacionais. Eles não podem ser isolados de influências externas nem analisados in loco.

Cabe, assim, pensar em uma proposição mais prática de como esses pontos poderão ser arranjados, levando em conta o triplo processo e/ou a tripla articulação a que Charlot (2006) faz referência. Já que não se pode ter controle sobre os objetos e as variáveis educacionais é necessário um arranjo que respeite esse caráter permeável da Educação. Nesse sentido, parece ficar implícita a necessidade do que Boaventura de Sousa Santos (2008) chama de "ecologia dos saberes".

No próximo item do artigo vamos buscar esclarecer esse conceito cunhado por Santos (2008) o confrontando com o diagnóstico dos campos de Bourdieu. Por fim, as contribuições desses dois autores ajudarão a refletir sobre um modo alternativo de construir autonomia disciplinar no campo da Educação (mas também nas ciências humanas e sociais de modo geral), em que há um contexto de reabertura ao diálogo e, gradativamente, vêm ganhando força os estudos sobre interdisciplinaridade e transdisciplinaridade.

\section{Outro Caminho de Autonomização}

Grosso modo, a ecologia dos saberes diz respeito a uma maneira de fazer extensão às avessas, trazendo a problemática social em sua concretude, no contexto estudado por Santos (2008), para dentro da universidade (o reduto da pesquisa). Parece, deveras, uma tentativa cabível de apreender o "objeto-humano" - tarefa que muitas vezes tem sido demasiado difícil para as ciências humanas e sociais - contemplando a tripla articulação imbuída num triplo processo. Essa ecologia ainda requereria um coletivo multifocal de olhares (de pesquisadores), pois buscaria abarcar um objeto excessivamente complexo. E, mesmo frente a conclusões irrefutáveis, as medidas advindas dessas conclusões teriam ainda de passar 
pelo crivo político e pelas políticas de Estado. O problema torna-se ainda mais complexo: como aproximar os atores da tripla articulação da pesquisa educacional de modo que os resultados desta tenham efeitos mais imediatos e horizontais junto àqueles e o campo da Educação escape, em alguma medida, do estatuto de refém (sendo, os resultados de sua ciência, implementados verticalmente pelo Governo) do Poder Público?

É justamente aqui que as ideias de Bernard Charlot, Boaventura de Sousa Santos e Pierre Bourdieu parecem ter certa confluência. O competente diagnóstico de Charlot (2006) ganha substancialidade no argumento de Bourdieu de que se deve compreender a tessitura social para poder transpô-la. A questão do diálogo intersubjetivo, embora esteja presente de modo diferenciado em Santos e Bourdieu, em ambos os casos parece sugerir caminhos para a construção de autonomia coletiva em campos com carência de autonomia científica.

Bourdieu refere-se ao campo científico de modo mais amplo e está preocupado em maior medida com a formulação de demandas com rigor científico, ele quer um "dispositivo de discussão coletiva orientado para a invenção de novas estruturas organizacionais próprias para favorecer essa integração na diferenciação [estrutural e funcional]" (BOURDIEU, 2004, p. 69). O autor propõe essa dinâmica como alternativa à busca de autonomia pelos campos científicos, para que estes possam escapar às demandas sociais externas mal formuladas, por exemplo, no âmbito midiático, pelos "filósofos da televisão".

Já Santos (2008) se atém mais à análise estrutural da universidade e seu aparente distanciamento dos objetos de estudo presentes na trama do social. A academia não deve afigurar-se a uma seara que empreende a monocultura dos saberes, mas a uma ágora que atribua credibilidade contextual aos saberes tradicionais e às práticas oriundas do mundo da vida. Em todo saber há incompletude e para suprir as lacunas do conhecimento científico por vezes é necessário o diálogo com saberes de outra ordem. Nas palavras de Santos (2004, p. 18), "o confronto e o diálogo entre os saberes é o confronto e o diálogo entre diferentes processos através dos quais práticas diferentemente ignorantes se transformam em práticas diferentemente sábias". 
Entretanto, as visões de Santos e Bourdieu são bastante antagônicas em diversos aspectos. Para Santos, a incorporação da sabedoria prática é uma condição para refundar as ciências sociais sob outros moldes. Para Bourdieu, o saber prático é meramente objeto de análise e a ciência é atributo dos profissionais do campo. Nesse sentido, para Bourdieu era impensável que a autonomia do campo dependesse de atores e instituições externas ao próprio campo, pois isso implicaria o risco de subordinação do campo científico em relação a outras esferas da vida social. Esta possibilidade é admitida por Santos e aqui compartilho de sua perspectiva, sobretudo em se tratando do campo educacional.

De qualquer modo, os "objetos" de estudo da Educação sempre apresentarão seu caráter em parte inacessível e incontrolável, pois serão inevitavelmente permeados pela subjetividade dos atores sociais que compõem o campo. Nas palavras de Minayo (2010, p. 172, grifo da autora), "a intangibilidade do objeto se explica pelo fato de que as ideias que se fazem sobre os fatos são sempre mediadas pelo sujeito (sua história, formação, ideias) e, portanto, são imprecisas, parciais e mais imperfeitas que a totalidade da observação". A dinâmica própria da totalidade, por seu turno, jamais estará isenta da subjetividade dos agentes articuladores da Educação. O ponto de partida das pesquisas educacionais é sempre complexo e cresce em complexidade à medida que se vai o investigando. As variáveis tendem a fugir cada vez mais do controle e as pesquisas tendem a se deparar com quesitos que advém de fora da dupla tríade enunciada por Charlot (2006).

A discussão que se dá no interior do campo não pode ocorrer sem a discussão prévia que se nutre da ecologia de saberes e do contingente de subjetividades que constituem os problemas educacionais sob pena de se eximir da tarefa de contemplar os problemas em sua complexidade (SANTOS, 2008). A consecução desses exercícios dialógicos, por si só já estaria contribuindo com a consideração da tripla articulação dos agentes constituintes do campo educativo.

Bourdieu (2003, p. 87, grifos do autor, tradução nossa) tem razão quando diz que "uma das características que mais diferenciam os campos é o grau de autonomia e, a partir disso, a força e a forma do direito de admissão imposto aos aspirantes a ingressarem neles". No entanto, diante da falta de autonomia do campo educativo e do contexto evidenciado 
por Charlot (2006), parece que a Educação pode utilizar a seu favor essa abertura em termos de direito de admissão de diferentes agentes, que não raro são também "objetos” de sua pesquisa. Aquilo que, para Bourdieu era inadmissível - um campo ter penetração de outras esferas da vida social - converte-se aqui numa potência atribuidora de autoridade científica ao campo educacional. Nisso concordamos com Santos (2008) e rompemos com Bourdieu. A Educação é uma esfera propícia para a ecologia de saberes e, enquanto campo científico, ganha autoridade na medida em que se abre a tal prática. Em outras palavras, talvez seja justamente seu potencial para a abertura à admissão de diferentes agentes que pode aportar com o constructo de objetos rígidos do ponto de vista educacional, dada a natureza heterogênea e suscetível ao diálogo interdisciplinar típica do campo educativo. Cláudio Dalbosco (2010, p. 60), por exemplo, corrobora essa visão ao argumentar que "a natureza intrínseca do âmbito problemático da pesquisa em educação remete ao diálogo com outras áreas”.

Isso leva a crer que, no caso particular da Educação, quiçá o processo de autonomização não passe necessariamente por uma elitização científica dos "clientes" dos produtos oriundos de pesquisas educacionais, mas aproximá-los dos pesquisadores a fim de obter uma melhor formulação dos problemas. Bourdieu (1983) explica que quanto maior for o grau de autonomia do campo, mais o produtor de conhecimento tende a ter como clientes outros produtores, porém a autonomia do campo educacional parece não passar somente pelo reconhecimento dos pesquisadores, mas, em última instância, também dos atores sociais que forjam a tripla articulação.

Se essa estratégia não concederia à Educação uma completa autonomia com relação a outros campos - pois sequer faria sentido perseguir tal intento - , capaz de lhe propiciar a implementação de um regime autárquico, pelo menos faria jus à certa regularidade formativa do campo por meio da melhor apreensão e consideração de seus objetos de pesquisas. O estatuto de campo de estudos, que detém dentre uma de suas particularidades a inter-relação de conhecimentos, por sua vez, poderia servir como argumento centralizador para transformar o campo educativo em uma espécie de ágora das discussões acerca da interdisciplinaridade, da 
transdisciplinaridade, de pressupostos fomentadores do diálogo advindos, por exemplo, da educação popular e de debates sobre saberes tradicionais.

O fato é que a preocupação com a integração e interação de saberes tem sido corrente no campo da Educação. A título de exemplo se pode citar a exaustiva discussão que vem sendo levada a cabo a respeito da transdisciplinaridade. O caráter transdisciplinar, antes de tudo, reconhece a lacuna deixada pelo conhecimento puramente abstracional. Não por acaso, assim, a transdisciplinaridade "[...] busca reconhecer os diversos níveis de realidade existentes, uma vez que a Realidade (o todo) não pode ser reduzida a uma única explicação coerente nem explorada em sua complexidade por uma ciência específica (COLLA, 2011)".

O conhecimento da Realidade, nesse sentido, não deve ser entendido como uma espécie de somatório das explicações que as disciplinas são capazes de produzir sobre ela e suas camadas, seus níveis de significação. Este se afigura mais a "uma rede de saberes acerca do real que, entrelaçados em contínuo diálogo, procuram compreender a complexidade desse mesmo real levando em conta a descontinuidade que ele encerra" (COLLA, 2011).

Ou seja, nessa perspectiva, a própria ideia de Realidade existe respaldada na coerência que se estabelece entre esses múltiplos saberes que a tentam aferir. Percebe-se, com isso, o caráter dialógico que transdisciplinaridade implica. A conexão do saber com o mundo da vida e a criação de uma esfera em que os conhecimentos possam dialogar são exigências do caráter transdisciplinar. Essa visão de Realidade é de extrema pertinência à Educação.

O que se quer problematizar aqui com esse exemplo é que os entraves para a busca da autonomia no interior do campo da Educação podem ser interpretados como indícios de que a autoridade científica, atribuidora de autonomia, talvez deva advir em grande medida das disposições a que o campo é propício, não da natureza de seus objetos. Assim, a autonomização da Educação enquanto campo passaria pelo diálogo acerca dos pontos de confluências entre as diversas disciplinas educacionais, mas também pela formulação de problemas a partir da tessitura do social, com a participação dos atores sociais, e tendo em conta a responsabilidade de fornecer feedback a esses agentes, seja na forma da apresentação de resultados de pesquisas, 
seja como esclarecimentos de rumos, objetivos e noções que norteiam tais pesquisas. Para tanto, a ecologia dos saberes seria fundamental. Em síntese, o principal desafio para obtenção de autoridade e autonomia científicas na Educação parece ser conseguir integrar essa multiplicidade de agentes de modo democrático na criação de demandas de pesquisa.

De qualquer modo, a discussão não deixaria de passar pela arregimentação dos especialistas, pelo seu traquejo capaz de resguardar à pesquisa o rigor científico e metodológico. A estratégia dialogal, especialmente no que diz respeito às ciências humanas e sociais, diz respeito ao reconhecimento da natureza complexa e subjetiva de seus objetos de estudo e das tramas em que está tecido.

Em outras palavras, a avaliação do estatuto disciplinar e a busca da autonomia dos campos relativos às ciências ditas "moles" - ou as ciências do espírito, como denomina Gadamer (1999) — devem considerar sua maleabilidade e predisposições a influxos advindos de demandas sociais e de outros campos. A natureza de cada campo definiria, assim, o que são autonomia e autoridade científicas e como é possível aferi-las sopesando as especificidades relativas aos próprios campos. Portanto, para se definir o que é a autonomia e a autoridade científicas em Educação deve-se levar em conta as especificidades do campo educacional, isto é, suas diferenças em relação a outros campos. Seu caráter dialógico e mais vulnerável a demandas sociais, nesse viés, se converte em potência autonomizante do campo e pode ser capaz de fazer com que este aufira maior autoridade científica.

É preciso ponderar, por exemplo, que a análise de Bourdieu se dá num contexto onde a herança paradigmática preponderante ainda é a da ciência moderna - recordemos o argumento de Thomas Kuhn (2004) acerca das revoluções científicas - cuja solidez do argumento se sustenta na objetividade e redução dos elementos constituintes dos "pontos de chegada" - como bem explica Charlot (2006). Isso também se dá no campo das ciências humanas e sociais, vale lembrar a preocupação de Durkheim (2007) em importar o modelo das ciências duras e utilizá-lo com o fim de imputar rigor científico à sociologia. Nesse viés, alguns dos postulados de Durkheim (2007) para as ciências sociais eram, por exemplo: que os fatos 
sociais fossem considerados como coisas; e que os princípios da causalidade fossem aplicados aos fenômenos sociais.

Tendo isso em mente e levando em conta que hoje as circunstâncias são outras, é interessante repensar a lógica da autonomia e autoridade científicas dos campos. Talvez, não necessariamente todos os campos sejam mais autônomos quanto menor forem as influências exteriores. Discussões em voga no meio acadêmico contemporâneo advogam a importância da inter e da transdisciplinaridade e isso se dá com especial ênfase nas ciências do espírito. O caráter admissível de alguns campos não estaria, nessa óptica, indo ao encontro dos próprios influxos capazes de alimentar e mover as discussões em seu interior?

Gadamer (1999) considera que as ciências humanas e sociais comportam uma herança humanista que as distingue da tradição da chamada "ciência moderna". Por mais que tenha existido muitos esforços como o de Durkheim (2007) que, inegavelmente, buscaram atribuir objetividade às ciências do espírito, as suas preocupações e objetivos são muito diversos. Na opinião de Gadamer (1999), o foco delas é a compreensão ou o entendimento. Compreender, para este filósofo, diz respeito ao entendimento de si próprio e dos outros num movimento recíproco e circular (que enfoca a particularidade, mas retrocede ao todo para o confronto compreensivo com determinada tradição) e não por acaso ele centra suas preocupações na práxis do diálogo e no círculo hermenêutico. Diálogo, para Gadamer (1999), não existe sem compreensão, bem como a compreensão requer o diálogo. A hermenêutica, por seu turno, é necessária quando não há a compressão-por-si-mesma e, desse modo, sugere o diálogo como alternativa de entendimento, mesmo que este se dê no âmbito da historicidade, ou seja, o intérprete confronta sua compreensão com determinada tradição (GADAMER, 1999). Num contexto em que ecoam tanto as pregações em favor do diálogo, o aporte teórico de Gadamer (1999) é animador.

Por outro lado, o paradigma da ciência moderna vingou. Este foi (e ainda é) hegemônico e aqueles que puderam se valer do modelo objetivista que ele encerra se beneficiaram de um status privilegiado. Nesse sentido, as ciências duras têm um estatuto disciplinar muito melhor 
definido nos moldes estipulados pela teoria dos campos de Bourdieu e os seus cientistas usufruem, por assim dizer, de uma autoridade científica muito menos contestável na instância social. Com vistas a esse contexto, não é de se surpreender que muitos pesquisadores das ciências do espírito tenham sido seduzidos pela tentação de objetivar suas pesquisas. Toda lógica da análise de Bourdieu acerca da obtenção de capital e autoridade científica e do grau de autonomia dos campos é extremamente pertinente, porém, na contemporaneidade, parece necessário rever a estrutura dos campos a serem analisados. Essa necessidade se faz presente sobretudo no que tange às ciências do espírito, levando em conta a sua tessitura heterogênea - e em processo de heterogeneização crescente - , a gradativa abertura ao diálogo interdisciplinar e a "atualidade da hermenêutica" enquanto alternativa à falta de compreensão, como Gadamer (1999) soube antecipar muito bem remontando à filosofia aristotélica.

Nesse sentido, as advertências de Lahire (2002) quanto à teoria dos campos se enquadra muito mais como uma proposta de renovação e atualização da teoria do que propriamente como uma crítica. Na medida em que o contexto se transforma é natural que para a sobrevivência das teorias, o mesmo curso seja seguido.

Em algumas de suas últimas exposições sobre o tema, o próprio Bourdieu parece reconhecer que uma dinâmica dialogal seria extremamente benéfica tanto para a ciência quanto para a sociedade. Nas palavras do autor,

Se existisse uma estrutura de deliberação coletiva, capaz de ultrapassar as divisões queevoquei, ainda agora, entre teóricos, práticos, básicos, aplicados, homens, mulheres e todo o resto e que enunciasse as questões, ao mesmo tempo, importantes e urgentes, certamente isso seria uma boa coisa tanto para a ciência como para a sociedade (BOURDIEU, 2004, p. 75). 
Se Bourdieu (2004) faz essas colocações em termos bastante gerais e as profere a um público de cientistas ${ }^{1}$, é possível pensá-las no contexto específico do campo educacional levando em conta suas especificidades.

É o diálogo compreensivo entre os múltiplos agentes externos e internos do campo que pode contribuir na constituição de um campo autônomo e reconhecido enquanto produtor de conhecimento com autoridade científica, válido e útil à práxis. Obviamente, não se trataria de um diálogo qualquer, mas um debate em camadas e em níveis distintos, em ordem crescente de cientificidade, desde a captação das demandas e identificação da sua real urgência ao campo social até a lapidação metódica dessas problemáticas e seu tratamento científico. Em última instância, parece conveniente que a discussão cientificizada se volte ao público, a fim de valorar a substância social de suas "descobertas". Eis um possível caminho autonomizante de uma ciência tão híbrida e influenciável.

Se não há como suprimir completamente o poder simbólico do ato científico, pode-se, porém - sobretudo num campo multifacetado e notadamente dialógico - apostar numa cofabricação de demandas científicas. Além disso, essa cofabricação dialogada entre agentes internos e externos ao campo, sejam eles cientistas ou não, parece seguir uma tendência nas Ciências da Educação. Tanto as discussões sobre a interdisciplinaridade, a transdisciplinaridade e os temas transversais quanto a valorização dos saberes populares e das culturas tradicionais vêm ganhando espaço no campo educacional e cada vez mais se consolidam enquanto temáticas de relevância no campo.

Espera-se que este ensaio sirva como um "início de conversa" e não como uma espécie de postulado. Assim, para finalizar, cabe uma indagação que deve ser tomada muito mais como estimuladora do diálogo do que como meramente retórica: a busca pela autonomia educativa não residirá em maior medida na ruptura do monopólio do academicismo, do

1 O livro Os Usos Sociais da Ciência: por uma sociologia clínica do campo científico, originou-se de uma conferência de Bourdieu seguida de debate organizados pelo grupo Sciences en Questions, Paris, no Institut National de la Recherche Agronomique (INRA), em 11 de março de 1997. 
cientificismo, fundando um campo de ciências da Educação ao mesmo tempo mais dialógico e ciente de seu caráter hermenêutico?

\section{Referências}

BOURDIEU, P. O campo científico. In: ORTIZ, R. (org.). Bourdieu - Sociologia. São Paulo: Ática, 1983. p. 122-155. (Coleção Grandes Cientistas Sociais, v. 39).

BOURDIEU, P. El oficio del científico: ciencia de la ciencia y reflexividad. Barcelona: Anagrama, 2003.

BOURDIEU, P. Os Usos Sociais da Ciência: por uma sociologia clínica do campo científico. São Paulo: Editora UNESP, 2004.

CHARLOT, B. A Pesquisa Educacional entre Conhecimentos, Políticas e Práticas: especificidades e desafios de uma área de saber. Revista Brasileira de Educação, Rio de Janeiro, v. 11, n. 31, p. 7-18, 2006.

COLLA, R. A. Mãe Natureza nos Anos Iniciais do Ensino Fundamental: abordagens, discursos e obstáculos em Educação Ambiental. Educação Ambiental em Ação, v. 38, 2011. Disponível em: <http://www.revistaea.org/artigo. php?idartigo=1137\&class=02>. Acesso em: 23 nov. 2018.

DALBOSCO, C. A. Natureza da Pesquisa em Educação: abrindo o leque de alguns problemas. In: HENNING, L. (Org.). Pesquisa, Ensino e Extensão no Campo Filosófico-educacional: possibilidades presentes no contexto universitário. v. 1. Londrina: Ed. Eduel, 2010. p. 41-66.

DURKHEIM, É. As Regras do Método Sociológico. São Paulo: Livraria Martins Fontes Editora, 2007.

DURKHEIM, É. Educação e Sociologia. São Paulo: Hedra, 2011.

GADAMER, H.-G. Verdade e Método: traços fundamentais de uma hermenêutica filosófica. Petrópolis: Vozes, 1999. 
KUHN, T. La Estructura de Las Revoluciones Científicas. Buenos Aires: FCE, 2004.

LAHIRE, B. Reprodução ou Prolongamentos Críticos? Educação \& Sociedade, Campinas, CEDES/Unicamp, ano XXIII, n.78, abr. 2002.

LIBÂNEO, J. C. Pedagogia e Pedagogos, Para Quê? São Paulo: Cortez, 2005.

MINAYO, M. C. S. O Desafio do Conhecimento: pesquisa qualitativa em saúde. São Paulo: Hucitec, 2010.

SANTOS, B. de S.; FILHO, N. de A. A Universidade no século XXI: para uma Universidade Nova. Coimbra: Edições Almedina, S.A, 2008.

SANTOS, B. de S. O Fórum Social Mundial: manual de uso. Madisson, dez. 2004. Disponível em: <http://www.boaventuradesousasantos.pt/documentos/fsm. pdf $>$. Acesso em: 23 nov. 2012.

Recebido: 28/06/2018

Received: 06/28/2018

Recibido: 28/06/2018

Aprovado: 05/10/2018 Approved: 10/05/2018 Aprobado: 05/10/2018 